\title{
UMA CIÊNCIA MÉDICA PARA A INFÂNCIA: A CONSTITUIÇÃO DA PEDIATRIA
}

Resenha do livro:

PEREIRA, Júnia Sales (2008). História, ciência e infância: narrativas profissionais no processo de singularização da pediatria como especialidade. Brasília: CAPES; Belo Horizonte: Argvmentvm, 198p.

Resenhada por:

Erica Piovam de Ulhôa Cintra

Em seu livro, Júnia Pereira, doutora em história pela Universidade Federal de Minas Gerais, apresenta a sua tese da constituição da pediatria no Brasil sob a ótica das narrativas e da argumentação dos profissionais que a tornaram uma especialidade da medicina em atenção às crianças. Enfatiza a importância do processo que levou ao que denominou singularização da pediatria no campo médico, num momento em que novas percepções a respeito da saúde/doença e do corpo doente, bem como da constituição de argumentos e justificativas no cuidado da infância, ocorreram.

Para a autora "o advento da pediatria assenta-se em transformações sociais, políticas e econômicas pelas quais viveria o Brasil já em meados do século XIX." (p. 15). E não sendo este um processo natural, tampouco linear, de constituição no interior da medicina, resultou do "diálogo com as transformações pelas quais já vinha passando a medicina europeia e em confronto com as experiências pelas quais passariam as instituições de formação e de atuação médico-profissionais no Brasil.” (p.17).

A periodização privilegiada por Júnia estende-se do final do século XIX a meados do século XX, período esse que, segundo a autora, demarca os primeiros movimentos favoráveis a uma formação acadêmica para a especialização médico-pediátrica no país, assim como indica a instalação dos primeiros consultórios particulares e de instituições de serviço médico destinadas ao atendimento da infância. As fontes de pesquisa se constituem essencialmente de periódicos especializados e da produção de médicos de crianças, dentre os quais: Moncorvo de Figueiredo, considerado o primeiro pediatra brasileiro, Moncorvo Filho, Martagão Gesteira e outros.

O discurso médico sobre a criança, observado nestas fontes, reforçará a dicotomia da figura da criança saudável versus a doente, a da criança normal versus a anormal; envidará práticas científicas e médicas que visassem frear a mortalidade infantil; e demarcará o importante papel que uma personagem em especial terá como protagonista: "da mãe ideal, cidadã virtuosa e aliada ao médico, em contraponto à mãe relapsa, afeita a curandeirismos e a práticas de auto-cuidado." (p. 20).

Discurso esse reconhecido por outras estudiosas que se relacionam com o tema aqui apresentado, mas que realizados ao mesmo tempo de Júnia, não compuseram o trabalho da autora (nem vice-versa), mas são exemplares do quanto essa preocupação tem obtido atenção de pesquisadoras da área da história das ciências e suas relações entre medicina e educação. A esse respeito cito Maria Martha de Luna Freire que reflete a "maternidade científica", em Mulheres, mães e médicos: o discurso maternalista no Brasil, em edição publicada pela FGV, em 2009, e ainda, Ana Paula Vosne Martins em "Vamos criar seu filho": os médicos puericultores e a pedagogia materna no século XX, no qual analisa a literatura médica de aconselhamento às mães, na tentativa dos puericultores de torná-las 
"mães-enfermeiras", publicado em artigo na revista História, Ciência, Saúde Manguinhos/Fiocruz, edição de 2008.

De modo geral, o livro de Júnia compõe-se de uma parte introdutória em que retoma elementos que conformaram originalmente a sua tese de doutoramento (tema de pesquisa, problema de pesquisa, pressupostos, fontes e recortes, e propriamente o texto do livro e sua organização). E divide-se em cinco capítulos com a seguinte proposição que comentamos.

No primeiro capítulo, intitulado Narrativas profissionais sobre a história da Pediatria, a autora tece uma análise da historiografia pediátrica brasileira nas duas vertentes observadas, uma que privilegia o caráter salvacionista e messiânico da narrativa (p.34-46), e outra na qual a pediatria dialoga com os elementos culturais e sociais (a mortalidade infantil, a reconfiguração da família, da mulher, da mãe, do profissional da saúde etc.), e sofre por isso alterações no discurso, aproximando-os de uma narrativa, como entende a autora, da história social da ciência e da infância. Comparecem aqui, Orlando Orlandi, cuja obra, segundo a autora, contribui para desmontar "o argumento da neutralidade da pediatria e da puericultura, trazendo à baila questões como as opções $e$ preferências profissionais, os jogos políticos-institucionais" (p. 48), e Carlos Rivoredo que, por sua vez, entende o nascimento da pediatria como, no campo da medicina, "resultado máximo de uma crescente ampliação da capacidade técnica e científica para cuidar e tratar de crianças" (p. 51).

No segundo capítulo, em $A$ especialidade de um tempo distinto da vida humana, sobressai um interessante debate acerca da especialização da medicina, com autores contemporâneos que estudam a história dessa disciplina e da formação do médico no século XIX; seguindo para as impressões dos periódicos especializados e de Martagão Gesteira, polêmico professor da Faculdade de Medicina da Bahia que, numa postura de médico generalista, não compreendia a pediatria como especialidade da medicina, nem a necessidade de uma cadeira específica para a moléstia de crianças, pois para ele " $o$ pediatra para se considerar perfeito tem necessidade de uma instrução médica muito vasta e muito profunda." (p. 60). A autora recupera a preocupação dos eugenistas em relação a institucionalização de uma medicina de crianças na década de 1920, o que para eles comprometeria a "impressão de conjunto" no estudo do fator hereditário; e contempla as ideias expressas no Congresso Nacional de Práticos de 1922, em que se discutiu a formação médica e o sentido de ser médico no Brasil levando-se em conta os três perfis à época: a do generalista, do especialista e do higienista (p. 62-63).

Ainda nesse capítulo, o destaque a Moncorvo de Figueiredo, personagem de importante projeção na institucionalização da pediatria no Rio de Janeiro no final do século XIX. O médico compreendia a pediatria como ciência distinta da medicina de adultos e teve participação ativa na constituição da Policlínica Geral do Rio de Janeiro, em 1881. Àquele ano, sob sua responsabilidade, criou a primeira cadeira de Clínica de moléstias de crianças, lecionada nessa Policlínica. No ano seguinte, Moncorvo de Figueiredo teria, a pedido do Ministro do Governo Imperial, Rodolfo Dantas, apresentado um Memorial que solicitava a criação de cadeiras nas escolas médicas imperiais e oferecia a Policlínica como campo de ação à Faculdade de Medicina do Rio de Janeiro. Nas academias imperiais, elementos de uma ciência de crianças estavam incluídos às cadeiras de Obstetrícia desde 1815, e à de Partos, moléstias de mulheres pejadas e paridas e de meninos recém-nascidos desde 1832. As cadeiras de Clínica médica de moléstias de crianças e Clínica cirúrgica de crianças seriam constituídas nas escolas médicas imperiais, posteriormente à ação de Moncorvo de Figueiredo na Policlínica Geral do Rio de Janeiro e no mesmo ano em que apresentou seu Relatório ao Ministro do Governo Imperial. Embora a apresentação dessa 
evidência, estranhamente, a autora deixa em aberto qualquer relação entre o Memorial de Moncorvo e a Reforma Leôncio de Carvalho, ambos de 1882 (veja p.68-71; 76-83).

No terceiro capítulo, em Pediatria, paidéia dos modernos, são discutidas as idealizações a respeito da morte infantil, do médico, da criança, da mulher, da mãe ideal. A autora explica que até às primeiras décadas do século $\mathrm{XX}$, período no qual a pediatria ainda não havia ocupado o seu lugar nos cuidados médicos da infância brasileira, eram as parteiras e os obstetras que davam as orientações iniciais a respeito dos cuidados com os pequenos. E que na virada do século (XIX-XX), as parteiras não-diplomadas foram alvo não somente dos obstetras, mas também de pediatras "vistas como concorrentes nãoautorizadas, em nada portadoras de um saber técnico e pouco afeitas aos rigores da prática médica." (p.103). A autora deixa evidente que o discurso pediátrico emergente encontrou nas mulheres as interlocutoras privilegiadas. Reforçando a narrativa da incapacidade de algumas mães (as pobres), e da ignorância de outras (as abastadas), o pediatra paulatinamente instalou-se "no exercício permanente da tutela materna e de seu aconselhamento."(p.104). A inserção do saber médico na educação escolar é outra via observada pela autora, na qual os pressupostos pediátricos chegavam às mulheres, mesmo que filtrado no sentido de resguardar aos círculos médicos os cuidados efetivos com as moléstias da infância, evitando assim a condenada automedicação, mas sem deixar de impor à família os preceitos a serem assimilados e adotados no que diz respeito à manutenção da saúde e da vida dos pequenos.

Nesse sentido, o encontro da pediatria com a puericultura (os cuidados dos pequenos na alimentação, no vestuário, no banho etc.), e a marcação da diferenciação entre seus saberes e práticas é apresentado: "a puericultura seria um saber a ser ensinado às moças nas escolas e a ser praticado pelas mães, e a pediatria seria o saber especializado, atributo do médico e daquele profissional de ciência, conselheiro da mãe e da professora." (p.104). Interpondo-se como profissional necessário entre a mãe e a criança (doente ou não), o pediatra assume para si esse campo profissional de intervenção e adota, por isso, uma nova conduta no atendimento clínico, ao que o médico Martagão Gesteira apresenta o seu modelo: pautado na calma, na escuta e na observação atenta aos sintomas dos pequenos (p. 105-108).

Nos dois últimos capítulos, Evolução, crescimento infantil e normalidade, e Saúde, alimentação e robustez, respectivamente, a autora reflete dois eixos centrais dos argumentos sobre a infância constantes nas narrativas dos médicos em defesa de uma medicina para crianças. No quarto capítulo, a autora discute a ideia de recapitulação em voga ao final do século XIX, em que a infância era vista como 'período selvagem' sendo, portanto, necessária a intervenção visando a sua evolução/civilização (p.110-118). Momento esse também no qual a pediatria formularia uma série de explicações para acompanhar, metrificar e verificar esse percurso de crescimento e de desenvolvimento do infante, ou mesmo "de uma linha progressiva de aumento de complexidade biológica" ( $\mathrm{p}$. 120), fundamentado numa ideia de "evolução gradativa e teleológica dos processos da vida humana." (p.121). Interessante aqui a apreciação de um dado que muda de perspectiva ao final do século XIX: "a mortalidade infantil deixaria de ser tratada como dado natural e passaria a ser encarada como problema e como algo a ser combatido" (p. 126). A partir desse momento, a incapacidade de evitar a morte precoce da criança, quando assistida, representaria o saber limítrofe do profissional, nesse caso, do obstetra, pois "até meados do século XIX, a medicina infantil era, basicamente, um derivativo da medicina de adultos, um atributo do médico obstetra, ou, quando muito, do médico de doenças." (p.126).

A medicina de crianças, portanto, sustenta sua singularização em dois pressupostos epistemológicos práticos compreendidos pela autora: a mortalidade infantil não é um dado natural, e as crianças são diferentes dos adultos por serem sujeitos em crescimento. No 
início do século $\mathrm{XX}$, a infância passa então a ser entendida como um tempo de vida que requer cuidados específicos e práticas clínicas também específicas e diferenciadas. A esse respeito é arrolado todo um detalhamento acerca dos problemas e doenças infantis pelos pediatras a pensar o que era entendido por normalidade no desenvolvimento infantil (p.129-132). A autora finaliza esse capítulo, com as considerações do ideário eugenista que difundia, dentre outros, os ideais de robustecimento físico (em destaque os Concursos de Robustez Infantil e a defesa de Moncorvo Filho a respeito), altamente presente no período em tela (p.132-139). Aliás, o tema do último capítulo (o quinto), enfoca a associação da robustez da criança (versus magreza) à saúde (p. 140-150), num painel que se incluirá a valorização da amamentação natural (p.151-153), e a difusão de outros produtos alimentares visando essa robustez dos pequenos (p.156-170), com a reprodução das imagens dos produtos veiculados nos periódicos especializados.

Júnia Pereira centrou-se no discurso médico e nos argumentos difundidos pelos pediatras a partir das revistas especializadas, a fim de compreender a constituição dessa especialidade médica no Brasil, analisando-os com propriedade ao longo do livro, e numa provocativa conclusão (confira p.173-184) que nos motiva a pensar nos encaminhamentos propostos pelos pioneiros de uma ciência médica para a infância. Ao desenvolver uma investigação consistente e articulada em tema que é de interesse à comunidade acadêmica, especialmente aos que refletem a produção da ciência médica e sua relação com a maternidade, a infância e a educação dos pequenos, enriquece a possibilidade de leitura desses objetos de estudo ao informar os caminhos de constituição de uma ciência médica para a infância, no caso, a pediatria. Com sensibilidade, a autora se apropria da metáfora da toalha, de empréstimo de José Murilo de Carvalho em Pontos e bordados (publicação da Editora da UFMG de 1998), e convida os leitores não apenas a leitura de suas páginas bem escritas e enredadas, mas a sentar-se a uma mesa em dia de banquete onde se destaca a toalha bordada - a metáfora da construção de sua narrativa, feita a várias linhas, bordados e muitos pontos, sem a pretensão, contudo, de se observar um ponto final.

História, ciência e infância é obra de referência aos estudiosos da infância, da medicina, da saúde e da educação dos pequenos, com especial assento aos historiadores da educação, pois é capaz de demonstrar a institucionalização de um saber especifico no campo médico (a pediatria) e dialogar com especialidades afins na área da educação (a puericultura), informando a prática de personagens (os médicos) junto às principais protagonistas de seus discursos (as mães); apresenta, portanto, narrativas e práticas que envolvem a saúde e a educação da infância brasileira especialmente no período aqui privilegiado, entre o final do século XIX a meados do XX. 